\title{
Destination Choices in Travel Decisions
}

\author{
Andi Desfiandi*, Faurani Santi Singagerda \\ Faculty of Economics and Business, IBI Darmajaya, Lampung Indonesia
}

DOI: $10.36348 / \mathrm{sb} .2019 . \mathrm{v} 05 \mathrm{i} 10.008$

| Received: 18.10.2019| Accepted: 25.10.2019 | Published: 31.10 .2019

*Corresponding author: Andi Desfiandi

\section{Abstract}

This study analyzes in determining the choice of foreign tourists traveled choice. Empirical studies conducted among foreign tourists entering Indonesia using the mixed logit model. The model is noted that the importance of the decision multistage process because the probability of a foreign tourist on vacation in Indonesia is highly dependent on tourist motivation associated with the attributes of the destination, travel arrangements, the information collected, previous experience, and socio-economic characteristics of individuals, by using a samples of 238 taken from the two entrances international flights during July-August 2017. The policy implication lowered to increase understanding for decisionmaking related to tourism industry where they are faced with the choice tourist destination that is heterogeneous.

Keywords: Tourism demand, decisions, preferences, strategy.

Copyright @ 2019: This is an open-access article distributed under the terms of the Creative Commons Attribution license which permits unrestricted use, distribution, and reproduction in any medium for non-commercial use (NonCommercial, or CC-BY-NC) provided the original author and source are credited.

\section{PRELIMINARY}

The tourism sector is one of the fastest growing economic sectors in the world where the number of global tourists is growing faster than predicted by the United Nations World Tourism Organization (UNWTO). This is based on the latest report from the UNWTO, one of the bodies of the United Nations (United Nations) which deals with tourism. In 2018, there will be 1.4 billion international tourist movements. A number in which the UNWTO does not expect will reach global tourism until 2020. The growth of tourism in recent years confirms that this sector, at present, is one of the most powerful drivers of economic growth and development.

Long-term estimates from the UNWTO in 2010 estimate 1.4 billion international arrivals in 2020 . It was reached two years earlier than expected, because of stronger economic growth, easier visa making and more affordable air transportation costs. From statistics released by the UNWTO world tourism development in 2018 shows that tourism to the Middle East and Africa is growing above the world average, which is $6 \%$, with a $10 \%$ increase in the Middle East and a $7 \%$ surge for Africa. Asia Pacific and Europe grew by $6 \%$. While tourists to America grow below the world average, with an increase of $3 \%$ in the same year.
The UNWTO forecasts for international tourism in 2019 are expected to be in line with a growth trend of $3-4 \%$. Uncertainty in Brexit, economic slowdown and geopolitical tensions as well as trade could cause travelers to wait for the results. While challenges for the development of the tourism sector such as the global economic crisis, rising world oil prices, natural disasters and terrorist attacks, are not good for the tourism sector. According to WTTC annual research into the economic impact and social importance of the sector, the global Travel \& Tourism sector grew at 3.9 percent to contribute a record of $\$ 8.8$ trillion and 319 million jobs to the world economy in 2018 [1] and 6.5 per cent of total exports, and can create 1 in 10 jobs worldwide and deliver 1 in 5 of all new jobs created in 2017.

The dynamics of the global tourism industry is facing the increasingly cheaper situation of competition, both at the regional and international levels between countries as tourist destinations. The more competitive a country as a tourist destination will attract more tourists to visit, tourists will bargain more money in the destination country. Gross Domestic Product (GDP), economic growth of the country, and people's economic welfare will increase. Therefore, each country will compete with each other to attract more tourists and spending $[2,3]$. 
Meanwhile, Asia Tourism Trends - 2018 'shows that international tourist arrivals in Asia and the Pacific grew 6\% in 2017 to reach 323 million, around a quarter of the world's total. Of all world regions of Asia and the Pacific, the second-most visited after Europe, has grown the fastest in international tourist arrivals since 2005. Arrivals increased an average of $6 \%$ per year, above the world average of $4 \%$ [4] .

Rapid economic growth in a region with over half of the world's population, coupled with rising air connectivity, travel facilitation and large infrastructure projects, have boosted international travel in the region. This has had a large impact on Asian destinations' tourism earnings, which has steadily increased from $17 \%$ of the world total in 2000 to $29 \%$ in 2017 . This is equivalent to US $\$ 390$ billion in tourism receipts.

Therefore, Asia and the Pacific plays a vital role as a source market as well, fuelling much growth in both regional and long-haul destinations. The region produced 335 million international travelers spending US $\$ 502$ billion in 2017, $37 \%$ of the world total. Around $80 \%$ of these visits were concentrated in Asia destinations. Outside the region, $56 \%$ of the long haul trips were to Europe.

On the other side, Indonesia as one of the countries in Southeast Asia has significant potential to develop into a world tourist destination, especially leisure tourism. The World Economic Forum (WEF) in Blanke [5] places Indonesia 6th and 38th of 140 countries in the world especially for the ownership of natural and cultural resources. This rating is well above the neighboring countries, such as Thailand and Malaysia.

However, with the potential of natural resources and a great culture, the achievements of Indonesian tourism can be said to be not optimal. Since the global economic crisis of 2008-2010, tourist arrivals and total tourist spending in Indonesia have tended to grow slowly. Similarly, Indonesia's market share of total visits and tourist expenditures in Southeast Asia continues to decline when the market share of Southeast Asian tourists to the world actually increases. This condition indicates a decline in the competitiveness of Indonesian tourism.

Even Singagerda et al. [6], in their research found the fact that Indonesian tourism is a substitute for tourism in other countries, especially in Southeast Asia such as Thailand, Singapore, and Thailand. This shows that Indonesian tourism is not yet a major destination for world tourism and is still an alternative choice for world tourists, especially if the world's top tourist destinations experience various issues related to price, security and policies. While, tourists are assumed to be faced with various alternative destinations, then choose a destination to maximize its utility [7]. Utility is a measure of satisfaction that consumers receive based on the use of goods and services [8], whereas every customer has a different level of satisfaction but they will try to achieve maximum satisfaction.

Beside that the study by d'Harteserre [5] explained that traveling is one of the preferences for consumers. When the decision to travel has been made, consumers choose various tourist destinations with varying degrees of substitution Tourists are confronted with income and time constraints. This is the underlying theory that choosing a tourist destination is one of the problems of consumer preference $[9,10]$.

This study is expected to be overcome the gap in the limited review of the tourism literature on tourism subtitutions, particularly in Southeast Asia. Based on the consumer choices framework, the use of mix logit models in this study is appropriately used to analyzed the determinants of the tourism decisions made by Spanish families, and Correia, Barros, and Silvestre [11], who analyzed repeat-choice behavior among tourists taking golfing holidays in the Algarve, Portugal.

In this study, competitiveness analyzed in relation to demand elasticity linking between the supply and demand sides of competitiveness. For each country of the tourist market, the elasticity of demand for Indonesia and its competitor countries is estimated and the results are compared for all market countries. This comparison result is used to analyze how successful a destination increases its demand compared to competitors Li et al. [12].

\section{LITERATURE}

Previous studies of substitute tourism can be grouped, namely studies of related dimensions and related research models. Patsouratis [13], shows that the main determinants of Greek tourism demand are price indexes and exchange rates. They also pointed out that Spain appeared to be Greece's main competitor. The exchange rate variant was found to be a significant determinant of long-term tourism demand in $50 \%$ of estimates. Real disposable income and replacement prices are found to have long-term, inelastic effects on tourism, while long-term relative price elasticities tend to differ widely across countries. Indonesia is the only country that has found that exchange rates have a significantly different effect on tourism than relative prices [14].

According to Syriopoulos [15]; Sinclair [16]; Vail \& Heldt [17]; Wall, \& Mathieson [18]; and Capittelo et al. [19], income elasticity shows large differences in tourism demand preferences between home countries and between traditional and emerging destinations. This shows that the price elasticity of self 
and substitutes shows the importance of effective prices in determining tourism receipts from destinations.

Barros et al. [20] Analyzed the process of choice of Portuguese tourists with respect to destinations that emerged in African countries. Empirical studies conducted among Portuguese tourists using models that underline the importance of the multistage decision process because the probability of a Portuguese tourist vacationing in an African country depends on a mixture of motivations regarding destination attributes, travel arrangements, information collected, prior experience, and socioeconomic characteristics of individuals. Whereas Mello et al. [21] Estimates of cross-price elasticities show substitutions between the closest neighbors, Portugal and Spain, and France and Spain. The results show the extent to which cross-country demand behavior becomes more or less similar over time due to changes in spending and effective prices. Spending elasticities were greater for Spain than France during the initial period, suggesting that tourism could help countries 'catch up' with their wealthier neighbors.

Michailidis \& Chatzitheodoridis [22] describe a multi-criteria decision-making framework used to evaluate and rank three tourist destinations, located in northern and central Greece based on elements of innovation which are a combination of different levels of image objectives of socio-economic data and purposeful personality. The methodology developed provides a user-friendly approach, promotes synergy between different stakeholders, and can open the way to consensus.

Correia [23] concluded the strategies by clusters are needed in order to account for the heterogeneity identified. Moreover, the combination of all former variables, which contribute substantially to a better understanding of tourism choice behavior, with the latter variables is needed to define a comprehensive strategy.

Gartner \& Ruzzier [5], investigated the concept of customer-based brand equity for tourism purposes. Specifically, this study investigated whether there is a difference between the update and tourists are repeated in their evaluation of travel destinations. The proposed theoretical models, which include the dimensions of awareness, image, quality, and loyalty, verified empirically for European travel destinations, Slovenia from the perspective of German tourists. The results imply that image dimensions and quality play the most important role in tourist evaluations of a destination, regardless of whether it is the first visitor or a repeater. The results also reveal important differences to the dimensions of awareness and loyalty between renewal and recurring tourists which have implications for tourism organizations in developing and implementing destination marketing strategies in foreign markets.

Carballo et al. [24], developed a new methodology for estimating the value of goal images, which combines two main advantages that is images of tourist destinations in the understanding cost-benefit analysis compared to economic valuation methods in terms of the image of tourist destination attributes.

Fernandes [25] identified the creativity strategy developed in Viana do Castelo, Portugal to build the infrastructure and environment needed where creative tourism can flourish and to create awareness and share best practices with goals that face similar challenges. As an emerging tourist destination, Vian a do Castelo is pursuing specific strategies for enabling innovation to differentiate tourism attractions, products and destinations. While Dwyer et al. [3] explore the ways in which the main driver in influencing the improvement of the global tourism industry until 2020. Exploration of this trend allows agents of important change, both in the supply and demand side of tourism, to be highlighted and discussed. In response, innovative strategies can be formulated by destination managers and tourism operators to avoid strategic shifts for their organizations and to develop tourism in a sustainable manner.

Mond [26], and Tan [12] presented a concrete example of the development of creative tourism and outlines some of the challenges involved in turning creative experiences into products that can be sold. Tan [12] found that there is 'outer interaction' and 'inner reflection' in building models of the creative experiences of tourists. External interaction refers to the interaction of tourists with the 'environment', 'people', and 'products / services / experiences', while inner reflection refers to' awareness / awareness', 'needs' and' creativity ', and these dimensions' interact 'in tourists throughout the experience. In addition, 'awareness' is a prerequisite for 'creative experience', which distinguishes it from other types of experiences.

Wuwei et al. [11] Uncovered a new concept of Creative Tourism, and discussed the reform and transformation of the Pattern of the Development of the Tourism Industry and suggested to overhaul the tourism industry system by thinking of creative industries. It explores the characteristics of creative travel and analyzes methods of using this new smart growth model to lead the transformation of the tourism industry around expanding industrial chains, expanding spatial chains, and demonstrating theme chains.

Chang et al. [24] investigated the relationship between motivation, tourist experience, perceived value and intention to revisit creative tourism destinations, where the concept of ever-evolving creativity has been 
introduced to tourism. This study aims to examine the psychology of tourist consumption in the context of creative tourism destinations. The results show that onsite tourism experiences are the most influential antecedents of the intention to revisit creative tourism sites so that they contribute to an increasing tendency to develop creative tourism products and services that include authentic local culture and arts in enhancing the tourist experience.

Evan et al. [27]; Pirnar [28]; and Sung [29] expressed the need for a strategic business plan that is comprehensive and innovative discuss the many factors that impact on the quality of tourism products including: population density, environmental concerns, safety and security of visitors, the problem of the season, and sensitivity to local culture so as to create competitiveness

\section{METHODOLOGY}

So far, not so many studies that discuss the creative travel, especially when discussing the traveler experience. This study used a qualitative approach or explorative to gain insight into the thoughts and experiences of tourists, where exploratory research usually used to reveal the significance of experienced [20], and is specifically suited to examine new areas where little is known about the phenomenon under study [22]. In this research, a grounded theory approach is used, which basically starts with symbolic interactionism $[8,30]$. The grounded theory approach is based on a series of qualitative research method that uses a series of systematic procedures, and data collection and analysis process simultaneously, in developing the theory of a phenomenon [8]. It refers to an innovative approach in developing a theoretical ideas and also a set of special tools in the analysis of inductive and deductive empirically to build conceptual understanding of the phenomena being studied [31]. It also allows researchers to produce concepts that have been conceptually established that explain the relationship between concepts that represent 'patterns of action and interactions between and between various types of social units.

In addition, grounded theory can assist researchers in examining tourism phenomena that have the potential to produce holistic theories, and also be able to increase understanding of human behavior that is not easily quantified [12]. In this study, samples will be taken using purposive techniques that enable the selection of rich and relevant sources of information that provide informed empirical material. The purposive sampling is not just to generate a set of representative samples, but also involves the selection of participants who have information have been actively involved in the activities of the type of experience [32].

Based on data from foreign tourist demand for Indonesian and Thai tourism, the main objective of this study is to determine the probability of foreign tourists choosing between Indonesian and Thiland tourism as a tourist destination, given the number of characteristics given, symbolized by vector xi. The model used in the article is as follows,

$$
U_{i j}=C_{0}+\alpha_{i j}+\beta X_{i j}+\varepsilon_{i j} \text {, }
$$

where Uij explains the utilities that come from options ( $\mathrm{j}=0.1$ ) made by individuals (i) and who filled out the questionnaire. $\mathrm{C}$ is a constant, defining average utility which is defined as the difference between Indonesian-Thai tourism. Whereas $\alpha \mathrm{ij}$ is a specific constant of random alternatives related to individuals and alternatives. And $\beta$ is a parameter vector of random attributes that are individual and alternative specific. Xij is an individual-specific and site-specific attribute vector. $\varepsilon \mathrm{ij}$ is an unobserved random term for a utility

$$
\alpha_{i j}=\gamma_{j}+\mu_{i j}
$$

where $\gamma \mathrm{j}$ is a parameter that identifies the average preference for alternative $\mathrm{j}$ in the population. $\mu \mathrm{ij}$ is assuming normally distributed random with an average of 0 and standard deviation $\sigma \mathrm{j}$, representing the marginal distribution $\alpha \mathrm{ij}$ and capture deviations from the average preference for alternative j. $\mu \mathrm{ij}$ are traveling to Indonesia that is distributed independently with the Gumbel distribution.

Alternative specific constants are random parameters that are allowed to vary between individuals. Where, each random parameter $\alpha \mathrm{ij}$ is assumed to exist with two components, averages, and random terms, which reflect variations in taste and are assumed to be normally distributed.

individuals and certain random disturbances that are not specifically observed and are a source of unobservable heterogeneity among individuals in preference to alternatives $\mathrm{j}$. The probability of individual opinion in choosing alternative $\mathrm{j}$, depending on $\mathrm{ij}$, can be explained by the binomial logit form: 


$$
P\left(j=1 \mid \mu_{i j}\right)=P\left(\beta, x_{i}\right)=\frac{e^{\beta} x_{i}}{1+e^{\beta x_{i}}}
$$

The unconditional probability is obtained by integrating the random terms out of the probability:

$$
P(j)=\int_{\mu_{y}} P\left(j / \mu_{i j}\right) g\left(\mu_{i j}\right) d \mu_{i j}
$$

This integral has no closed form, and allows for the exact maximum value to occur. In this case, the Integral has the expected value and can thus be estimated by simulating, and the simulated loglikelihood (SLL) function is maximized [33, 34]. For parameter valueof $\mu \mathrm{ij}$, the value is taken from distribution aij. By using the value of this draws, the product of the standard logit can be calculated. This process was repeated for much of the draw, and the result is taken as the probability of selection forecast:

$$
S P(j)=\frac{1}{R} \sum_{r=1}^{R} P\left(j / \mu_{i j}\right)
$$

$\mathrm{R}$ is the number of draws in the simulation, and SP (j) is the probability of simulation chosen by someone $\mathrm{j}$. The maximum likelihood that is simulated is maximized as:

$$
S L L=\sum_{i=1}^{I} \ln P(j)
$$

The estimated parameter is one that can maximize SLL. Because the bias in SLL is reduced due to an increase in the draws numbers. Train [34] suggests using the draws sequence with the Halton method as a random draws. Based on the choices made by foreign tourists to Indonesia, the article was possible to use a mixed logit model. And to test the hypothesis that will be proposed, in this case, we will used a logit representation mixture assume that the possibility of choosing Indonesia over Thailand tourism can be explained by the cumulative logit probability function of exogenous variables $\mathrm{Xi}$, Prob (variable selection / type). On this basis, we will estimate the probability mentioned above for selection of $i$ as.

$$
\operatorname{Pr}\left(\text { Choice }_{i} \mid v_{i}\right)=\int_{-\infty}^{+\infty} P\left(\beta, v_{i}\right) N\left(\beta_{21} \mid \mu_{21}, \sigma_{21}\right) d \beta_{5}
$$

where $\mathrm{N}(\bullet)$ is the normal distribution and,

$$
v_{i}=\beta_{0}+\sum_{i=1} \beta_{i} X_{i}+\varepsilon_{i}
$$

where $\mathrm{Xi}$ is the variable of a questionnaire distributed to these populations. We measure the probability that the tourist $\mathrm{V}_{\mathrm{i}}$ stated that he chose Indonesia than Thailand tourism ( $1=$ yes, $0=$ no), labeling Indonesia tourism and measure $X_{i}$ as the observed characteristics.

Thus from Eq (2), (7), and (8) the equation as follows:

$$
\begin{gathered}
V_{i}=\beta_{0}+\beta_{1} \text { nature }+\beta_{2} \text { culture }+\beta_{3} \text { climate }+\beta_{4} \text { ethnic }+\beta_{5} \text { exotic }+ \\
\beta_{6} \text { security }+\beta_{7} \text { distance }+\beta_{8} \text { brochure }+\beta_{9} \text { hospitality }+\beta_{10} \text { price }+ \\
\beta_{11} \text { accessability }+\beta_{12} \text { facilities }+\beta_{13} \text { previous experiences }+\beta_{14} \text { cleanliness }+ \\
\beta_{15} \text { convenience }+\beta_{16} \text { friends'recommendation }+\beta_{17} \text { Frequent coming }+\epsilon_{1}
\end{gathered}
$$

The empirical studies were carried out using a questionnaire administered trough immigration inspection in July and August 2017 using stratified random sampling techniques from foreign tourists leaving Indonesia through the international airports of Soekarno Hatta (Jakarta) and Ngurah Rai (Bali) with the main purpose of determining their reasons for choosing certain destinations .

Foreign tourist that leaving from Indonesia totaled 95 in July and 142 in August 2017. Tourist represented $30.2 \%$ of foreign tourist leaving Indonesia through Soekarno Hatta airport and $29.65 \%$ of foreign 
tourist leaving from Bali via Ngurah Rai airport, which involved 238 tourist arrivals. At a response rate of $38.2 \%$ nonresponse questions were obtained, in which the testing procedure based on Dillman [35] was adopted. The first test for this problem involves defining randomly selected groups of respondents, distributing questionnaires and testing the answers. These respondents maintain the stated value, ensuring the accuracy of the responses.

The general characteristics of these respondents were that they traveled as couples since approximately half of the sample were male (52\%), with an average age of 27 . This profile leads to an overall definition of the responding tourist as young, middle-class couples, with a family that includes at least one child. Other characteristics of the sample are presented in table 1.

The test involved contacting random subsamples from those who have refused to fill out a questionnaire to learn the reasons they did not respond. As a result, several explanations were given. The first reason is the stated individual privacy policy, which is a common obstacle to the questionnaire. The second reason is the lack of time available to complete the questionnaire. The third reason is saturation, related to filling in too many questionnaires. From these three reasons, it can be stressed that nonresponders have the same characteristics as those who respond, building representation from a questionnaire that is fully filled out.

The study also used 4 hypotheses that proposed to test by means of the adoption of the mixed logit model. Hypotheses 1 (budget) is the tourism budget travelers who choose Indonesia as an important variable in determining vacation. Prices and budget constraints are a major influence on the choice of destination, although most researchers use price to explain the choice of destination $[36,23]$. In the article, the travel budget as a proxy for income in testing this hypothesis.
Hypotheses 2 (destination attributes): A tourist who chooses to visit Indonesia is interested in destination attributes such as nature, culture, climate, ethnic values, exotic environments, security, distance, promotion, hospitality, accessibility, facilities, previous experience, cleanliness, comfort, and the frequency of arrival. In line with $\mathrm{Chi} \& \mathrm{Qu}$ [37]; Nicoletta \& Servidio [36] who analyzed that the image of a tourist destination and its choices are influenced by destination attributes.

Hypotheses 3 (socio-demographic characteristics) such as age group, social class, and friends' recommendation are important variables for tourists who choose to vacation in Indonesia. Beerli \& Martin [38] claimed that the destination's image and choices are influenced by variables such as age, income, past experience, and personal values.

Hypotheses 4 (information): Information is important in determining the decision of a tourist who chose Indonesia as a destination. Perceptions derived from information previously obtained will help consumers to clarify and evaluate alternative objectives [39]. The source of the information being considered is promotion, previous experiences, and friends' recommendation.

\section{DISCUSSION}

From the results showed that the sample of non-responders related to age and gender, the results did not differ significantly, for age, $\chi^{2}=8.53$, with $\mathrm{p}=$ .05 , for sex with $\chi 2=7.55$ at $\mathrm{p}=.05$ ). Therefore, we can confirm that 238 tourists who filled out the questionnaire were representatives of foreign tourists.

A general characteristic of these respondents is that they travel as a couple because about half of the sample are men (47\%), with an average age of 35 years. This profile leads to the overall definition of a tourist who respond as young couples, middle-class, with a family that includes at least one child. So that other characteristics of the sample are presented in table 1.

Table-1: The Result of Variabels Characterization

\begin{tabular}{|c|c|c|c|c|c|}
\hline Variables & Descriptions & Minimum & Maximum & $\mathbf{M}$ & SD \\
\hline & Dependent Variables & & & & \\
\hline & Dummy Variables & 0 & 1 & & \\
\hline \multicolumn{6}{|c|}{ Budget attributes hypothesis } \\
\hline Budget & $\begin{array}{l}\text { Travel budget }(1=\text { less than } 1000 \\
\text { USD, } 2=1000-3000 \text { USD, } 3=3000 \\
-5000 \text { USD, } 4=5000-10,000 \\
\text { USD, } 5=\text { more than } 10,000 \text { USD }\end{array}$ & 1 & 5 & 1.575 & 1.002 \\
\hline Price & $\begin{array}{l}\text { What is important of tourism price } \\
\text { for your decision? }\end{array}$ & 2 & 5 & 5.926 & 1.905 \\
\hline \multicolumn{6}{|c|}{ Destination attributes hypothesis } \\
\hline Nature & $\begin{array}{l}\text { What is the importance of nature on } \\
\text { your decision }\end{array}$ & 1 & 4 & 1.981 & 1.147 \\
\hline
\end{tabular}


Andi Desfiandi \& Faurani Santi Singagerda., Sch Bull, Oct 2019; 5(10): 593-603

\begin{tabular}{|c|c|c|c|c|c|}
\hline Culture & $\begin{array}{l}\text { What is important of cultural } \\
\text { attraction? }\end{array}$ & 1 & 5 & 5.776 & 13.285 \\
\hline Climate & $\begin{array}{l}\text { What is important of climate for } \\
\text { your decision? }\end{array}$ & 1 & 4 & 4.984 & 1.306 \\
\hline Ethnic & $\begin{array}{l}\text { What is important of ethnic } \\
\text { composition for your decision? }\end{array}$ & 1 & 4 & 4.725 & 1.285 \\
\hline Exotic & $\begin{array}{l}\text { What is important of exoctic for } \\
\text { your decision? }\end{array}$ & 1 & 5 & 5.276 & 1.794 \\
\hline Security & $\begin{array}{l}\text { What is important of security on } \\
\text { your decision? }\end{array}$ & 1 & 5 & 5.742 & 1.902 \\
\hline Distance & $\begin{array}{l}\text { What is important of distace for } \\
\text { your decision? }\end{array}$ & 2 & 4 & 4.465 & 1.703 \\
\hline Promotion & $\begin{array}{l}\text { What is important of promotion for } \\
\text { your decision? }\end{array}$ & 1 & 4 & 4.722 & 1.678 \\
\hline Hospitality & $\begin{array}{l}\text { What is important of hospitality for } \\
\text { your decision? }\end{array}$ & 4 & 5 & 5.750 & 1.827 \\
\hline Accessability & $\begin{array}{l}\text { What is important of accessability } \\
\text { for your decision? }\end{array}$ & 1 & 5 & 5.288 & 1.780 \\
\hline Facilities & $\begin{array}{l}\text { What is important of facilities on } \\
\text { your decision? }\end{array}$ & 2 & 5 & 4.985 & 1.468 \\
\hline $\begin{array}{l}\text { Previous } \\
\text { experiences }\end{array}$ & $\begin{array}{l}\text { What is important of previous } \\
\text { experiences for your decision? }\end{array}$ & 2 & 5 & 4.462 & 1.105 \\
\hline Cleanliness & $\begin{array}{l}\text { What is important of cleanliness on } \\
\text { decision? }\end{array}$ & 1 & 4 & 4.018 & 1.083 \\
\hline Convenience & $\begin{array}{l}\text { What is important of convenience } \\
\text { factors for your decision? }\end{array}$ & 1 & 5 & 5.429 & 1.725 \\
\hline $\begin{array}{l}\text { Frequent } \\
\text { coming }\end{array}$ & $\begin{array}{l}\text { What is important of frequent } \\
\text { comming for your decision? }\end{array}$ & 2 & 5 & 4.294 & 1.017 \\
\hline \multicolumn{6}{|c|}{ Socio Demographic attributes hypothesis } \\
\hline Age & The age of tourist interviewed & 18 & 72 & 37.724 & 21.625 \\
\hline Social Class & $\begin{array}{l}\text { In terms of income } \\
1=\text { low class, } 2=\text { middle class, } 3= \\
\text { high class }\end{array}$ & 1 & 3 & 2.487 & 0.892 \\
\hline $\begin{array}{l}\text { Friends' } \\
\text { recommendation }\end{array}$ & $\begin{array}{l}1=\text { without recommendation, } 7= \\
\text { extremely important }\end{array}$ & 1 & 7 & 3.689 & 1.122 \\
\hline
\end{tabular}

Sources: Train (2003); authors (2017)

Table 2 shows the observed variables that have statistical significance in this model, the questions asked, and the appropriate scale. The hypothesis proposed above is tested through the adoption of a mixed logit representation which assumes that the probability of choosing Indonesia instead of Thailand can be illustrated by the cumulative logit probability function of the exogenous variable, Xi, Prob (choice / type). To estimate mixed logit models, and for comparison purposes, standard logit models are used.

This study uses a standard logit model, by applying the test RESET. These results provide evidence logit model specification errors, due to unobserved heterogeneity; this depends on the explanatory variables mentioned earlier. In this study, we also applied the HAL test [40] which uses the likelihood ratio procedure to test the greatest substitution.
First, we assume that it depends on all explanatory variables. Next, we apply the classic selection procedure. The results show evidence of unobservable substitution depending on budget and age, encouraging the estimation of mixed logit models with random coefficients for these variables.

The parameter model $\beta$ correlates changes in the explanation of $\mathrm{Xi}$ variables to changes in response probability. While parameter signs indicate the direction of the relationship, they are not directly interpreted as marginal changes in the mean value of the dependent variable.

This is because of the form of nonlinear distribution function. Based on the global model, using transformation $100(\mathrm{e} \beta-1)$, it can be said that each additional unit of income from foreign tourists results in an increase of around $6.02 \%$ in the possibility of Indonesia tourist arrivals, and this model fits the data. 
While homoscedasticity test process supported by the possibility of error $\left(\chi^{2}\right.$ calc $\left.=32.5\right)$ for the logit model mix. The Chi-square tests reject the hypothesis that the sets of coefficients were not statistically different from zero at $1 \%$ significance level.

Asymptotic statistics indicate whether the estimation of certain parameters is statistically different from zero, that is, if the variable impacts on the likelihood of Indonesian tourism. Opportunities for tourist arrivals to Indonesia are positively correlated and statistically significant with some exogenous variables.

These differences mean that choosing Indonesia is related to various determinants of consumer behavior. Tourism authorities can use the conclusions from this article to differentiate their marketing strategies towards tourists who come to Indonesia, classify individuals based on variables heterogeneous and adopt a generic strategy for variables homogeneous.

The study found a significant correlation between the probabilities of choosing Indonesian tourism which is an exogenous variable. In the calculation of the mixed logit model, the results that show the probability of choosing Indonesian tourism increase positively and have a statistically significant impact on the budget, culture, ethnic, distance, promotion, previous experiences, frequent coming, group age, and social class even though the budget and age variables are random parameters

The probability of selecting Indonesian tourism has a significant negative influence by exotic, security, hospitality, price, accessibility, cleanliness, and convenience, whereas friend's recommendation and exotic are not statistically significant negative effect.

When comparing the standard logit with each logit mixture using Lagrange test at $p=0.00$, the results show that the logit mix is a more appropriate model specification. The fact is found the existence of random parameters that indicate the influence of these variables have a large variance on the sample.

In addition, the results show that some variables can facilitate decisions while others inhibit. The first step, we accept Hypothesis 1, based on a statistically significant positive results for the budget indicates that the budget appears to be a facilitator of choice [23, 39].

Table-2: Parameter of estimation

\begin{tabular}{|c|c|c|c|c|}
\hline \multirow[t]{2}{*}{ Variables } & \multicolumn{2}{|c|}{ Standard Logit } & \multicolumn{2}{|c|}{ Mixed Logit } \\
\hline & Coefficient & t-stat & Coefficient & t-stat \\
\hline \multicolumn{5}{|l|}{ Random effects } \\
\hline - Budget & - & - & 0.047 & $2.822 *$ \\
\hline - Age & - & - & 0.052 & $2.803 * *$ \\
\hline Budget & 0.049 & 0.308 & 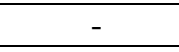 & $\begin{array}{l}- \\
\end{array}$ \\
\hline \multicolumn{5}{|l|}{ Price } \\
\hline Nature & -0.592 & $-3.237 *$ & -5022 & $-3.088 *$ \\
\hline Culture & 0.565 & $3.258 *$ & 0.3996 & $4.005^{*}$ \\
\hline Climate & 0.495 & $3.005 *$ & 0.400 & $3.928 *$ \\
\hline Ethnic & 0.157 & 2.369 & 0.175 & 3.078 \\
\hline Exotic & -0.488 & -2.995 & -0.385 & -4.065 \\
\hline Security & -0.078 & $-0.752 *$ & -0.012 & $-0.675 *$ \\
\hline Distance & 0.226 & $1.107 * *$ & 0.085 & $2.063 * *$ \\
\hline Promotion & 0.285 & $3.257 *$ & 0.209 & $3.155^{*}$ \\
\hline Hospitality & -0.318 & $-3.062 *$ & -0.195 & $-3.829 *$ \\
\hline Accessability & -0.615 & $-3.375^{*}$ & -0.525 & $-4.874 *$ \\
\hline Facilities & 0.482 & $3.589 *$ & 0.392 & $3.273^{*}$ \\
\hline Previous experiences & -1.205 & $-2.870 * *$ & -1.052 & $-1.220 * *$ \\
\hline Cleanliness & -0.752 & $-1.127 * *$ & -0.375 & $-1.058 * *$ \\
\hline Convenience & -1.108 & $-4.244 *$ & -1.055 & $-3.847 *$ \\
\hline Frequent coming & 0.957 & 3.572 & 0.784 & 3.299 \\
\hline Age & 0.007 & 1.114 & - & - \\
\hline Social Class & 0.158 & $2.788^{*}$ & 0.056 & $2.225^{*}$ \\
\hline Friends' recommendation & -1.854 & -4.227 & -1.525 & -3.871 \\
\hline \multicolumn{5}{|l|}{ Statistics of the model } \\
\hline Obs & 238 & & 238 & \\
\hline Log likelihood & -112.385 & & 112.025 & \\
\hline
\end{tabular}


Andi Desfiandi \& Faurani Santi Singagerda., Sch Bull, Oct 2019; 5(10): 593-603

\begin{tabular}{|l|c|c|l|l|}
\hline Specification Test & Statistic & $\mathrm{p}$ value & & \\
\hline RESET on standard logit & -3.192 & 0.0100 & & \\
\hline Hal on standard logit & 20.826 & 0.0001 & & \\
\hline LR : standard vs mixed & 39.52 & 0.0002 & & \\
\hline
\end{tabular}

Sources: Stern (2016), author (2017),

Note: RESET $\square \square$ detects misspecification in the logit model and was performed with $\hat{\beta}^{\prime} \chi_{i}^{2}$, HAL $\square \square$ detects evidence of heterogeneity in the logit model depending on budget and age; LR $\square \square$ likelihood ratio test. Dependent variable: $1 \square \square$ choosing Indonesia for vacation, $0 \square \square$ elsewhere). * Statistically significant at $0.01, * *$ statistically significant at 0.05

By using Langrange test, to compare with the standard logit logit mixture, obtained statistical test $\mathrm{p}=$ 0.00 this indicates that a mixture logit model specifications more precise than the mixed logit. The fact that a parameter is random means that the influence of these variables has a wide variance so it is samples used vary widely.

The results showed that some variables can provide decision while others discourage it, where Hypothesis 1 is acceptable, based on the statistical results obtained by the positive and significant impact on the budget variables. These results are consistent with previous studies [36, 11], and also indicates that the budget appears to be an important element in determining the choice of tourists visiting Indonesia.

We accept Hypothesis 2, because culture, culture, distance, promotion, and facilities are positive and statistically significant, confirming previous research conducted by Chi \& Qu [37]; and Nicoletta \& Servidio [36].

However, the characteristics of other objectives (ie, natural, exotic, security, friendliness, accessibility, prior experience, and comfort) are statistically negative. This result confirms that destinations with the view attribute act as chosen variables and facilities act as cosntrains.

We accept Hypothesis 3 because age and social class are statistically significant this confirms previous research by Nicolau \& Mas [36]. However, the results also showed that friend recommendations were statistically insignificant, and showed that those who chose Indonesia were, on average, 27 years old and could be categorized as upper-middle-class individuals who subjectively evaluated social classes, traveling without their children.

We accept Hypothesis 4 for the promotion of positive and statistically significant; agree with previous studies [39]. This indicates that promotion can facilitate tourists to choose Indonesian tourism. However, the information obtained from previous experience statistically significant negative.

\section{CONCLUSION}

The study makes three contributions, the first thing shows that the decision to take a vacation is supported by social and economic profile of the traveler, previous experience, and attributes of the destination is considered, validate previous studies [23]. The second contribution of this research can improve understanding of why tourists traveling to Indonesia. Third, this research can provide a better understanding of the importance of Indonesian tourism abroad and the decision making process involved.

This article shows that the mixed logit model can be used to determine the variables that can support or constraints on the decision of tourists to visit Indonesia. Assuming that tourists it are heterogeneous, so that the models used are estimated based on the probability that a tourist would choose Indonesia instead of Thailand, and the results support the hypothesis majority.

The overall conclusion is that foreign tourists who choose Indonesia are consumers who choose a vacation based on the price offered. Motivation of goals is a matter of culture, ethnicity, and climate. They use the information obtained from promotional strategy to plan their vacations. They are generally travelers with comfort motives, such as price, safety, previous experiences, accessibility, hospitality, and facilities.

Regarding the managerial implications of this research, it is valuable for the parties involved, especially tourism policy stakeholders to have a deeper insight into the motives behind the choice of foreign tourists coming and visiting Indonesia, and, with greater awareness of what that consumers need more than just vacations, they can pay special attention to the statistically significant variables estimated in the model when defining the tourism destinations offered. In addition, policy makers can investigate the reasons behind some negative coefficients, such as those related to promotion. A possible explanation is that promotion, especially the effect of word of mouth from the results of previous experiences and recommendations of friends to be reckoned with. Alternatively, it is possible that respondents to the questionnaire underestimate the role of promotion in their decision making process. Furthermore, the industry must adapt specific programs for different groups related to nature, facilities, safety and comfort. 
As well as a marketing strategy to be reckoned with the fact that it tends to be relatively homogeneous in many variables, with the exception of age and budget. Therefore, generic marketing strategies to the budget, for example, must be targeted at a group of tourists who are budget groups so that it allows different budget group travelers to make different choices. In other words, the policy maker must be able to create an appropriate pricing strategy in accordance with the intended tourist target based on the ability of the consuming group. In addition, appropriate promotion is also needed to increase the tourism potential of these destinations by selling more local services that contribute to increasing consumer confidence in choosing Indonesia.

This article has two main limitations associated with data collection methods. First, the problem is relatively short time span. Second, the sample procedure adopted is limited to two Indonesian entrances (airports); so that the conclusions drawn are also quite limited. So that, it required a deep study about motivation and traveler decision in choosing travel destinations.

\section{REFERENCES}

1. Sanjeev, G. M., \& Birdie, A. K. (2019). The tourism and hospitality industry in India: emerging issues for the next decade. Worldwide Hospitality and Tourism Themes.

2. Crouch, G. I., \& Ritchie, J. B. (1999). Tourism, competitiveness, and societal prosperity. Journal of business research, 44(3), 137-152.

3. Dwyer, L., Edwards, D., Mistilis, N., Roman, C., \& Scott, N. (2009). Destination and enterprise management for a tourism future. Tourism management, 30(1), 63-74.

4. Richards, G. (2018). Cultural tourism: A review of recent research and trends. Journal of Hospitality and Tourism Management, 36, 12-21.

5. Gartner, W. C., \& Ruzzier, M. K. (2011). Tourism destination brand equity dimensions: Renewal versus repeat market. Journal of Travel Research, 50(5), 471-481.

6. Sari, D. P., Singagerda, F. A., Prajoko, E., \& Purnomo, C. K. (2014). Application of ImportancePerformance Analysis method to improve the quality of services in South Jakarta land office. In FIG Congress 2014, Engaging the ChallengesEnhancing the Relevance (pp. 16-21).

7. Crouch, G. I., \& Ritchie, J. B. (1999). Tourism, competitiveness, and societal prosperity. Journal of business research, 44(3), 137-152.

8. Goulding, C. (2005). Grounded theory, ethnography and phenomenology: A comparative analysis of three qualitative strategies for marketing research. European journal of Marketing, 39(3/4), 294-308.
9. Couch, F. J., Farid, L. M., DeShano, M. L., Tavtigian, S. V., Calzone, K., Campeau, L., \& Shattuck-Eidens, D. (1996). BRCA2 germline mutations in male breast cancer cases and breast cancer families. Nature genetics, 13(1), 123.

10. Darvas, Z. (2012). Real effective exchange rates for 178 countries: a new database.

11. Correia, A., Santos, C. M., \& Barros, C. P. (2007). Tourism in Latin America a choice analysis. Annals of Tourism Research, 34(3), 610629.

12. Tan, S. K., Kung, S. F., \& Luh, D. B. (2013). A model of 'creative experience'in creative tourism. Annals of tourism research, 41, 153-174.

13. Patsouratis*, V., Frangouli, Z., \& Anastasopoulos, G. (2005). Competition in tourism among the Mediterranean economics, 37(16), 1865-1870.

14. Webber, A. G. (2001). Exchange rate volatility and cointegration in tourism demand. Journal of Travel research, 39(4), 398-405.

15. Syriopoulos, T. C. (1995). A dynamic model of demand for Mediterranean tourism. International review of applied economics, 9(3), 318-336.

16. Sinclair, M. T. (1998). Tourism and economic development: A survey. The journal of development studies, 34(5), 1-51.

17. Vail, D., \& Heldt, T. (2000). Institutional factors influencing the size and structure of tourism: Comparing Dalarna (Sweden) and Maine (USA). Current Issues in Tourism, 3(4), 283-324.

18. Wall, G., \& Mathieson, A. (2006). Tourism: change, impacts, and opportunities. Pearson Education.

19. Capitello, R., Agnoli, L., \& Begalli, D. (2015). Chinese import demand for wine: evidence from econometric estimations. Journal of wine research, 26(2), 115-135.

20. Barros, C. P., Butler, R., \& Correia, A. (2008). Heterogeneity in destination choice: Tourism in Africa. Journal of Travel Research,47(2), 235246.

21. Mello, M. D., Pack, A., \& Sinclair, M. T. (2002). A system of equations model of UK tourism demand in neighbouring countries. Applied Economics, 34(4), 509-521.

22. Michailidis, A., \& Chatzitheodoridis, F. (2006). Scenarios analysis of tourism destinations. Journal of Social Sciences, 2(2), 41-47.

23. Correia, A., Santos, C. M., \& Barros, C. P. (2007). Tourism in Latin America a choice analysis. Annals of Tourism Research, 34(3), 610629.

24. Carballo, M. M., Araña, J. E., León, C. J., \& Moreno-Gil, S. (2015). Economic valuation of tourism destination image. Tourism Economics, 21(4), 741-759.

25. Fernandes, C. (2011). Cultural planning and creative tourism in an emerging tourist 
destination. International journal of management cases, 13(3), 629-636.

26. Mond, H. G., Hillock, R. J., Stevenson, I. H., \& McGAVIGAN, A. D. (2007). The right ventricular outflow tract: the road to septal pacing. Pacing and clinical electrophysiology, 30(4), 482-491.

27. Evans, M. R., Fox, J. B., \& Johnson, R. B. (1995). Identifying competitive strategies for successful tourism destination development. Journal of Hospitality \& Leisure Marketing, 3(1), 37-45.

28. Pirnar, I., Bulut, C., \& Eris, E. D. (2012, September). Improving the performance and competitiveness of tourism establishments by means of innovation: trends and applications. In Proceedings of IRAT ,Enlightening Tourism "Conference, Naples, Italy (p. 211).

29. Sung, T. K. (2015). The creative economy in global competition. Technological Forecasting and Social Change, 96, 89-91.

30. Mills, J., Bonner, A., \& Francis, K. (2006). Adopting a constructivist approach to grounded theory: Implications for research design. International journal of nursing practice, 12(1), 8-13.

31. Sekaran, Uma, and Roger Bougie. Research methods for business: A skill building approach. John Wiley \& Sons, 2016.

32. Morse, J. M. (2010). Sampling in grounded theory. The SAGE handbook of grounded theory, 229-244.
33. Bhat, C. R. (2001). Quasi-random maximum simulated likelihood estimation of the mixed multinomial logit model. Transportation Research Part B: Methodological, 35(7), 677-693.

34. Train, K. E. (2009). Discrete choice methods with simulation. Cambridge university press.

35. Dillman, D. A. (1978). 1978 Mail and Telephone Surveys: The Total Design Method. New York: John Wiley.

36. Nicoletta, R., \& Servidio, R. (2012). Tourists' opinions and their selection of tourism destination images: An affective and motivational evaluation. Tourism Management Perspectives, 4, 19-27.

37. Chi, C. G. Q., \& Qu, H. (2008). Examining the structural relationships of destination image, tourist satisfaction and destination loyalty: An integrated approach. Tourism management, 29(4), 624-636.

38. Beerli, A., \& Martin, J. D. (2004). Factors influencing destination image. Annals of tourism research, 31(3), 657-681.

39. Alegre, J., Mateo, S., \& Pou, L. (2010). An analysis of households' appraisal of their budget constraints for potential participation in tourism. Tourism Management, 31(1), 45-56.

40. Stern, H. S. (2016). A test by any other name: P values, Bayes factors, and statistical inference. Multivariate behavioral research, 51(1), 23-29. 